Artículos de investigación 


\title{
Enunciación
}

\section{Maestros y escuelas ante la violencia: resistencias desde el lenguaje como acontecimiento estético y sociocultural}

\author{
Teachers and Schools before Violence: Resistance from Language as an Aesthetic \\ and Sociocultural Issue \\ Érica Elexandra Areiza Pérez*
}

\begin{abstract}
Resumen
El artículo presenta resultados de una investigación doctoral que se pregunta por las subjetividades políticas de maestros y maestras en la Comuna 13 de Medellín. El propósito del trabajo es develar las experiencias pedagógicas que los educadores han llevado a cabo en este territorio para contribuir a la restitución del tejido social, a la construcción de paz y a la generación de nuevas expectativas de vida para los niños, niñas y jóvenes. Esta apuesta se desarrolla a partir de una investigación narrativa, cuyos fundamentos teóricos y metodológicos enfatizan en la potencia del relato en la construcción epistémica y en las configuraciones sociales y subjetivas. En los hallazgos se destacan los sentidos que adquiere el lenguaje como acontecimiento de resistencia y de saber en el que la lectura, la literatura y las artes tienen un lugar esencial. Asimismo, se reconoce cómo el accionar político de los maestros en contextos afectados por la violencia cobra una importancia sustantiva para resistir frente a lo establecido, frente a la desesperanza y la pérdida.
\end{abstract}

Palabras clave: lenguaje, maestros, subjetividad, resistencia, violencia.

\begin{abstract}
This article presents the results of a PhD research that asks for teachers' political subjectivity in Medellín's Comuna 13. The purpose of this project is to unveil the pedagogical experiences that teachers have carried out in this territory to contribute to the restitution of the social fabric, the construction of peace, and the generation of new life expectations for children and youngsters. This effort is carried out through a narrative research, whose theoretical and methodological basis emphasize the strength of the story in epistemic shaping and in social and subjective settings. The findings of this study highlight the meanings acquired by language as a resistance, knowledge, and life event, in which reading, literature, and arts play a central role. Likewise, this research recognizes how teachers' political actions in contexts affected by violence gain substantial importance in resisting what is established, hopelessness, and loss.
\end{abstract}

Keywords: teachers, violence, subjectivity, language, resistance

* Magíster en Literatura Colombiana y doctoranda del Doctorado en Educación de la Universidad de Antioquia. Profesora de la Universidad de Antioquia. Correo electrónico: erica.areiza@udea.edu.co

Cómo citar: Areiza Pérez, É., E. (2021). Maestros y escuelas ante la violencia: resistencias desde el lenguaje como acontecimiento estético y sociocultural. Enunciación, 26(1), 15-28. DOI: https://doi.org/10.14483/22486798.16652

Artículo recibido: 11 de julio de 2020; aprobado: 30 de septiembre de 2020 


\section{Introducción}

En Colombia, las escuelas y los maestros han sufrido daños enormes como consecuencia de la violencia vivida durante décadas. Distintas regiones del territorio nacional podrían testimoniar las heridas, los dolores y la desolación dejados por el accionar de distintos grupos armados que se han impuesto con vehemencia en la cotidianidad de las aulas y en sus alrededores. Cuánta conmoción generan, por ejemplo, las fotografías de las escuelas en ruinas de los Montes de María, entre los departamentos de Córdoba y Sucre, que forman parte de la obra Silencios, del artista colombiano Juan Manuel Echavarría ${ }^{1}$, o las que Jesús Abad Colorado ${ }^{2}$ da a conocer con paisajes escolares derruidos en municipios de Antioquia como San Francisco, uno de los que integran la extensa lista de los pueblos que sufrieron tomas guerrilleras. Cuánto duele también recordar a Puerto Torres, una pequeña localidad ubicada en Belén de los Andaquíes, municipio del departamento de Caquetá, que entre los años 2000 y 2003 vivió el horror de la que se conoce como "la escuela de la muerte" (Centro Nacional de Memoria Histórica, 2014), un centro de tortura y entrenamiento militar del Frente Sur Andaquíes, de las Autodefensas Unidas de Colombia, que se instaló justo donde funcionaba el Colegio Gerardo Valencia Cano de esa localidad. De esos salones que antes cobraban vida con el aliento diario de niños, niñas, jóvenes y maestros, no queda más que un lugar inhóspito, despojado, triste.

En otros casos, cuando el maestro ha persistido en su comunidad, no ha estado exento de intimidaciones y del miedo que paraliza y enmudece.

1 En su propuesta fotográfica, Echavarría ha tenido un interés especial por las escuelas abandonadas como consecuencia del conflicto armado. En la serie Silencios, del año 2010, es posible apreciar 62 fotografías que tienen como centro aulas y tableros en ruinas, la mayoría pertenecientes a los Montes de María, entre los departamentos de Sucre y Bolívar. A través de este enlace se puede acceder a la página donde se encuentra un contenido representativo de su obra: http://www.jmechavarria.com/

2 Este periodista y fotógrafo colombiano es uno de los que mejor ha captado las imágenes dejadas por la guerra en Colombia. Durante 26 años ha recorrido el territorio nacional y ha convertido su cámara en un testigo sensible de los gestos, los paisajes, las ruinas, el dolor, la esperanza y la belleza en medio del horror.
Un miedo que determina las formas de relacionamiento con los otros y que se desata a propósito de esa memoria del terror que se va configurando en zonas afectadas por el conflicto armado, tal como lo enuncia Lizarralde (2012) en su trabajo "Ambientes educativos y territorios del miedo en medio del conflicto armado: estudio sobre escuelas del Bajo y Medio Putumayo". Allí, la presencia y los enfrentamientos entre guerrillas, paramilitares y fuerza pública dejaron sus temibles sombras en el recuerdo de los habitantes. De esta manera, lo que se ha impuesto en este y en muchos otros contextos educativos del país son unas políticas de muerte en la que se anula la voz y se diezma cualquier forma de participación, como lo sostienen Cortés, Pérez y Guerra (2016) en su texto "La escuela colombiana: entre la nuda vida y la biopotencia". Dichas políticas se concretan en el asesinato de maestros y en las amenazas que reciben; en muchos casos, hasta los temas que enseñan se convierten en objeto de vigilancia. Sumado a esto, muchos estudiantes sufren amenazas o son reclutados para que formen parte de las estructuras de grupos al margen de la ley.

Esa realidad hostil ha sido puesta en tensión por muchos maestros y directivos que, convencidos de que la muerte no puede dominar o mantener su señorío, como lo sugiere el poeta Dylan Thomas (1955), han encarado la adversidad y generan espacios para la vida, allí donde los días se empeñaban en su opacidad. De acuerdo con Cortés, Pérez y Guerra (2016), relatos de maestros y directivos de instituciones educativas de Putumayo, Sincelejo y Caquetá, evidencian el compromiso que estos han asumido para no permitir que los estudiantes se decanten por la guerra y por las armas, antes bien, han aunado esfuerzos para que encuentren en el estudio su motivación esencial, al tiempo que han acudido a distintas estrategias para desnaturalizar el conflicto en el imaginario de los jóvenes. Además, han promovido distintos espacios de participación desde actividades artísticas y culturales, escenarios que fungen como puntos de fuga para desplegar la invención y la creatividad en favor de 
la vida. Una experiencia similar se reseña en Casanare, específicamente en el municipio de Tauramena, donde los maestros disuadían a los jóvenes que sentían atracción por las armas con diversidad de juegos (Cortés, Pérez y Guerra, 2016). Gracias a ello, seguían habitando un lugar en el aula y no en las filas de los actores armados.

Otra apuesta que vale la pena resaltar por su acogida a los jóvenes que renuncian a la guerra para volver a ocupar un pupitre es relatada por Pilar Lozano en Historias de un país invisible (2017). Uno de los relatos contenidos en el libro se sitúa en Toribío, Cauca, uno de los municipios de Colombia que más tomas guerrilleras recibió. En una de sus escuelas, la mayoría de los estudiantes pertenece a la comunidad indígena nasa. Como parte de los sustentos pedagógicos que se adoptaron está el principio que en su lengua reza Wet wet Fxinzenxi, que significa: "lo que se haga debe llevar al buen vivir". Del distanciamiento del conflicto y de los propósitos volcados a la paz surge una especie de himno creado por profesores y estudiantes. En esta composición se pueden apreciar estos trazos de vida:

Volvamos a cantar / volvamos a cantar / en nuestra lengua / volvamos a cantar /

en nuestra lengua / volvamos a poner / volvamos a poner / nuestro sombrero

y nuestra ruana negra, / que los espíritus toquen la flauta, / el viento toque el tambor, /

la lluvia toque maracas / la canción la canto yo. (Lozano, 2017, p. 17)

De este modo, con la recuperación de la lengua, con su distanciamiento de las armas, estos estudiantes recobraban el lenguaje de la posibilidad, el tono común, las cosmogonías del canto originario, el vínculo con la naturaleza y su trama de significados. No cerró sus oídos la escuela al advenimiento de esta musicalidad, antes bien, animó una composición coral donde los instrumentos eran la extensión de un necesario pronunciamiento en favor de un vivir distinto en sintonía con otras melodías para ese territorio fatigado de conflictos.

En otra región de la geografía colombiana, específicamente en San Carlos, también se encuentran maestros que persistieron en periodos en los que las hostilidades fueron más severas. Este municipio del Oriente Antioqueño vivió, entre 1997 y 2006, una violencia desmedida que, además de las víctimas, dejó la lamentable estadística de una de las zonas con mayor número de desplazados. No obstante, muchos maestros permanecieron en sus comunidades y trazaron una cartografía de esperanza es esos paisajes crepusculares.

Tampoco las escuelas y los maestros de algunas ciudades del país han escapado a esa violencia desmedida que, como si se tratara de un pulpo inclemente, va extendiendo sus enormes tentáculos para poner a callejear sus fines.

\section{Las heridas de la escuela en la ciudad: el caso de la Comuna 13}

Medellín es un centro urbano que ha tenido que vivir, durante las últimas cuatro décadas, esas pisadas de la guerra que han aplastado centenares de vidas y violado sistemáticamente los derechos humanos. Algunas de sus comunas han presenciado con mayor dureza las disputas protagonizadas por distintos actores vinculados a las milicias, la guerrilla, los paramilitares, las fuerzas del Estado, el narcotráfico y las bandas delincuenciales. Dentro de los sectores que mayores daños han sufrido está la Comuna $13^{3}$. Allí han hecho presencia todas las estructuras enunciadas, lo que ha generado múltiples confrontaciones armadas y fracturas sociales. Las particularidades topográficas, la marginación, la pobreza, la deficitaria presencia institucional y la ubicación estratégica hicieron de este un territorio en disputa, un suelo expedito para emprender

3 Medellín está organizada, desde el ámbito político-administrativo, en seis zonas: nororiental, noroccidental, centro oriental, centro occidental, suroriental, suroccidental. Estas zonas están conformadas por comunas, las cuales suman 16 y cada una está integrada por varios barrios. La Comuna 13 se ubica en la zona centro occidental, una de las seis zonas en las que se divide la ciudad. 
proyectos políticos y económicos desde las enmarañadas cumbres de la ilegalidad.

Un detenimiento en estos actores y en los periodos más crudos del conflicto dan cuenta, de acuerdo con el estudio La huella invisible de la guerra: desplazamiento forzado en la Comuna 13 (Grupo de Memoria Histórica, 2011), de un dominio de las milicias en la década de 1990. En sus inicios se trataba de jóvenes que se agrupaban para reaccionar y defenderse del accionar delictivo de combos y pandillas, esto es, se justificaban en la necesidad de garantizar seguridad y tranquilidad en las comunidades. Luego fueron tomando fuerza y constituyeron grandes estructuras armadas cuyas funciones iban desde acabar con la vida de personas que desde su perspectiva representaban una amenaza para el orden social, hasta la mediación en conflictos familiares y barriales. En ese contexto surge en 1996 uno de los grupos de milicias que mayor poder ejercieron en dicha zona, a saber, los Comandos Armados del Pueblo (CAP), quienes se presentaban como independientes. Ellos eran el referente de gobierno y autoridad en este lugar.

Las guerrillas del ELN y las FARC vieron también en este territorio una oportunidad clave para expandir y posicionar su proyecto subversivo en la ciudad. Por ello su aparición en la Comuna a finales de los años noventa, con frentes de milicia y células insurgentes que entrarían también en escena con sus propias estrategias. Entre tanto, luego de algunas incursiones iniciales en $1997^{4}$, los grupos paramilitares avanzaron en su ofensiva más letal al final de la década y participaron en la confrontación armada de los primeros años del nuevo siglo.

Había otro actor ausente en muchos actos anteriores, pero ahora dispuesto a recuperar su papel protagónico. El inmenso telón dejaba al descubierto el rostro militar del Estado representado en la fuerza pública, acaso porque el inicio de una nueva década no podía pasar a la historia como

$4 \quad$ Los primeros grupos que incursionaron en la zona formaban parte del Bloque Metro. Luego se posicionó el Bloque Cacique Nutibara, "el cual se consolidó entre los años 1998 y el 2000 como la principal organización paramilitar en la ciudad" (Grupo de Memoria Histórica, 2011, p. 71). la continuidad de una ausencia histórica en aquel territorio. La forma de compensar esa precariedad institucional fue a través de una decidida presencia que encontraba su sentido más contundente en una serie de operativos. El año 2002 pasó a la memoria como el periodo con mayor número de intervenciones militares en la zona, entre ellas, las dos de mayor impacto y despliegue: la Operación Mariscal y la Operación Orión ${ }^{5}$.

En medio de esta disputa territorial, algunas escuelas sufrieron daños en la infraestructura, al tiempo que tuvieron que encarar la deserción escolar y los daños psicosociales generados en la comunidad educativa. En los años de las peores hostilidades las aulas sobresalían por el ausentismo de sus estudiantes porque no era posible salir de la casa, porque había que irse de la Comuna cuanto antes, o porque la pérdida de un ser querido ocupaba tristemente la atención y la vida. En el tiempo de las operaciones militares Ilevadas a cabo en 2002, un gran número de estudiantes no pudo asistir a las instituciones y otros jamás volvieron. Algunas instituciones quedaban inermes entre el fuego cruzado, y los profesores y los escolares se veían obligados a permanecer por varias horas en el piso para proteger la vida. Ocurrió también que muchos centros educativos sirvieron como refugio en los periodos más convulsos, esto es, entre 2000 y 2003. Establecimientos como la Institución Educativa La Independencia acogían a decenas de familias que se desplazaban de sus hogares porque en estos no había garantía de seguridad.

De ese tiempo hasta el presente ha habido una recomposición del mapa de actores; bandas y combos se han mantenido vigentes en una irrenunciable disputa por el territorio. De ahí que las conflictividades violentas no cesen y que se habite una calma tensa que propicia, de pronto, periodos de mayor miedo y agitación.

\footnotetext{
5 La Operación Mariscal se llevó a cabo en mayo, y la Operación Orión, el 16 de octubre de 2002. Estas pretendían enfrentar a las guerrillas, desterrarlas de la zona y recuperar la presencia del Estado. Estas intervenciones generaron grandes hechos de violencia y desapariciones que aún siguen en la impunidad. En estos operativos participaron el Ejército, la Policía, miembros del DAS y del CTI, así como integrantes de la Personería, la Fiscalía y la Procuraduría.
} 
Es en esta compleja trama de tensiones donde se sitúa la pregunta por el lugar de los maestros en la Comuna, por las experiencias pedagógicas que han aportado a la generación de nuevos horizontes para el vivir en este territorio. Se trata de una indagación por el despliegue de su subjetividad, de su accionar ético y político en un ámbito social y educativo que supone resistencias y gestos de acogida. Asimismo, se sitúa la inquietud por el lenguaje y su carácter edificante en los procesos de formación que se Ilevan a cabo en el ámbito escolar.

\section{Subjetividades políticas y lenguajes para un nuevo comienzo: un horizonte conceptual}

Frente a las lógicas de la violencia que han tenido lugar en la Comuna 13, ¿cómo entender la escuela cuando cotidianamente asiste a las cicatrices, las marcas y los rastros que estas dejan? Se quedaría corta si no va más allá de un proyecto que instaura sus hegemonías, que ejerce su poder de normalización y disciplinamiento (Foucault, 1975); desviaría su razón de ser si se agota en un lugar para la fabricación (Meirieu, 1996); reduciría sus sentidos si se obstina en promover una educación ajena a la problematización y decantada por una educación bancaria (Freire, 2005) agotada en la acumulación de contenidos. Los territorios y sus circunstancias sociohistóricas redefinen también a las escuelas; no son estructuras físicas donde se imparten unos conocimientos estandarizados dictados por unos reproductores que se dirigen a cuerpos mudos y resignados. Las escuelas tienen que ver con espacios donde sucede la vida, donde el lenguaje se despliega en sus distintas posibilidades semióticas y las subjetividades se configuran en un acontecer constante.

La pregunta por la subjetividad se presenta, en la contemporaneidad, no solo como una fuerte y decidida preocupación de diversos campos de investigación, sino como una íntima inquietud sobre sí mismo que se despliega en distintas formas de saber y de poder, entre prácticas, imaginarios y utopías que inscriben al sujeto en un conjunto de relaciones y tensiones. Por ello, lo propio de la subjetividad es su devenir, su acontecer en los pliegues de una cartografía que combina trazos bien delineados con marcas borrosas de un hacerse continuo e inacabado.

Desde la antigüedad hasta nuestros días, la subjetividad se ha gestado en prácticas de dominación y en ámbitos de libertad que complejizan su carácter y la hacen portadora de una historicidad, no solo desde el acumulado de sentidos que se han construido en cada época, sino en las trayectorias de vida de cada sujeto. Sentidos y trayectorias mediados por el lenguaje, por vínculos intersubjetivos, por diversidad de representaciones culturales. La subjetividad, sugiere Torres (2006), entraña una "naturaleza simbólica, histórico-social, intersubjetiva, vincular" (p. 94).

En este sentido, la subjetividad encara el desafío de los ámbitos social y político, la agitada arena de lo público. Devenir sujeto se imbrica así, en prácticas instauradas en procesos sociales, formas de saber, discursos y estrategias de poder donde se juegan procesos de sujeción y dominación, pero también resistencias que le crean fisuras al denso muro de lo instituido.

Así pues, frente a las hostilidades permanentes, ante la pérdida y el miedo, ¿qué sentido cobran las subjetividades políticas de los maestros? Estas se sitúan como configuraciones que quiebran lo habitual, que crean lo posible en la tensión entre lo instituido y lo instituyente (Castoriadis, 1997), que generan otros órdenes de realidad (Torres, 2006). Revestidas de inconformidad frente a las hostilidades y las vejaciones, estas pueden sacudir la resignación y la indiferencia para dar lugar a una educación que interpela los determinismos históricos (Freire, 2005) para posicionar otros relatos de vida y otras formas de humanidad, que se distancian de aquellas que acallan toda manifestación de lenguaje como posibilidad de encuentro y generación de comunidad.

Los relatos de los maestros participantes en la investigación hablan de esa necesidad de 
reconocer en los niños, niñas y jóvenes que habitan las aulas, a sujetos situados en realidades históricas atravesadas por confrontaciones, muertes, violencia y miedo, pero cuyo destino puede transitar por otros caminos cuando se interpela la resignación y se generan territorios de paz como apuesta ética esencial. Una ética en diálogo con Boff (2002), como cuidado que entraña afecto y compasión: "Se trata de salir del propio círculo y entrar en la galaxia del otro en cuanto otro, para sufrir con él, alegrarse con él" (p. 103). De igual modo, para Mèlich (2010), filósofo catalán de generosa producción bibliográfica sobre la ética y la narración en contextos marcados por el dolor como consecuencia de la guerra,

[...] compasión significa acompañar y acoger. [...] una ética de la compasión se concibe como la forma en que los seres humanos [...] tenemos que habérnoslas con el mundo y con los otros, la forma de responder de él y ante él. (p. 95)

Ese gesto ético de acogimiento y de hospitalidad se devela en experiencias pedagógicas en la Comuna, donde la música es una de las aliadas de los maestros para inspirar en los jóvenes un ritmo vital distinto a los pálpitos que les sacuden el corazón ante las realidades violentas que viven sus barrios. De ahí que compongan y entonen canciones con un alto contenido social y empuñen con fuerza los lapiceros que van trazando las letras, como queriendo sugerir que esas son las herramientas que deberían estar en todas las manos juveniles; porque qué hacen las armas en tantas manos, qué hacen estas sustituyendo las composiciones que pueden inventar otros guiones para una nueva época. A estos brotes artísticos cultivados en el terreno de la invención se unen el teatro, la literatura, la pintura, la danza.

Así pues, el lenguaje se renueva para que los estudiantes den lugar a un nuevo pronunciamiento del mundo. Un pronunciamiento que, como señala Freire (2005), se concreta en relaciones dialógicas avivadas por el amor, la esperanza, el derecho a decir la propia palabra y a respetar los silencios. En el ejercicio de su acción política, algunos maestros de la Comuna se han pronunciado y han elevado su voz para que no se impongan los lenguajes de la guerra, las expresiones que crean regímenes verbales que anulan y despojan de toda opción discursiva. En este sentido, han optado por un lenguaje concebido como una práctica sociocultural que se teje en relaciones de saber, poder y resistencia, al tiempo que posibilita la participación en la vida ciudadana. Se trata de formas de enunciación que se distancian del carácter instrumental de la comunicación o del atiborramiento de información, para instaurar espacios de formación que posibiliten el despliegue del pensamiento crítico y de la experiencia sensible, así como la incidencia en las relaciones intersubjetivas y en los distintos ámbitos de la esfera social.

Esta visión del lenguaje enfatiza también en una perspectiva estética que se da el permiso de habitar distintas manifestaciones artísticas y que, unido a ello, anima espacios de creación, caminos po(e)sibles (Durán, 2013, p. 103), provocaciones para hacer del arte vida o de la vida una obra de arte como sostenía Foucault (2008). De este modo, en escenarios escolares donde los gritos han generado aturdimiento, donde la guerra ha dibujado los rostros de la hostilidad, donde el miedo ha inhibido la palabra, donde se le han querido poner grilletes a la imaginación, las distintas posibilidades expresivas ensanchan los horizontes y recobran para la escuela las tramas simbólicas que acompañan y permiten nombrar los dolores, las bellezas y las miserias.

Se generan, de este modo, acontecimientos que le crean fisuras a la cotidianidad y propician remezones en el pensamiento, en las formas de sentir y de obrar. De acuerdo con Bárcena (2000), "Ios acontecimientos nos obligan a 'hacer una experiencia' en el sentido de padecerla, de sufrirla, de ser alcanzado por algo que no nos deja impasibles, ni en el pensar ni en el actuar" (p. 14). Acontecer como borde desde donde se resiste y se crean nuevas rutas de vida y de acción formativa. 


\section{Perspectiva metodológica, participantes y fases}

La construcción metodológica se fundamenta en una investigación biográfico-narrativa, perspectiva que realza el valor epistemológico, antropológico y político de la narración en la configuración de la experiencia humana y en las distintas prácticas sociales. En el ámbito de la educación, la investigación biográfico-narrativa se asienta, de acuerdo con Bolívar (2002), "dentro del 'giro hermenéutico' producido en los años setenta en las ciencias sociales" (p. 4); giro que interpela las formas de producción de conocimiento desde la perspectiva positivista y se decanta por una perspectiva en la que los sujetos recuperan su voz y su lugar como constructores de realidad y de significado producto de una experiencia interpretativa donde la vida, los fenómenos sociales y la enseñanza se asumen como textos (Bolívar, Domingo, Fernández, 2001; Bolívar, 2002). Se reivindica, desde este enfoque, la subjetividad como una construcción social que se potencia en la dialogicidad, en sus despliegues afectivos, biográficos, políticos. Narrar constituye, pues, una forma de construcción de saber que pone en primer plano la voz, la dimensión sensible y las trayectorias de los sujetos en su interrogación frente al mundo, frente a sí mismo y frente a los otros.

Desde tiempos inmemoriales, los relatos han acompaño el devenir de las distintas culturas y comunidades. Unido a ello, han favorecido el posicionamiento crítico, la rebeldía frente a lo establecido, la interpelación de regímenes y discursos dominantes. Tan potentes como necesarias resultan las distintas posibilidades de la narración en contextos que, como los afectados por la violencia, abundan en historias de dolor y silenciamiento. Por ello insiste Ricoeur en que la historia del sufrimiento reclama narración (Ricoeur, 2004). La perspectiva narrativa delinea los bordes para nuevos acontecimientos enfocados en órdenes de realidad y habitualidades que introducen la grieta de lo posible, el como si (Bruner, 2013) de un tiempo narrativo que reinventa las tramas y se resiste a la naturalización de la cotidianidad.

En esta apuesta investigativa participan seis maestros y maestras que han ejercido su profesión en instituciones educativas de la Comuna 13 entre 1996 y 2020. El proceso se estructura en cuatro fases. En la primera se realiza un acercamiento a este territorio desde los ámbitos histórico, sociológico, pedagógico, comunitario. La segunda comprende tres métodos, a saber: biografías magisteriales orientadas a la reconstrucción narrativa de las trayectorias formativas y profesionales de los maestros, así como de sus posturas pedagógicas, sus visiones de mundo; relatos de experiencias enfocados en la construcción de narrativas orales y escritas relacionadas con experiencias pedagógicas que los maestros han agenciado en sus escuelas, como respuesta curricular a las condiciones socioculturales de ese territorio, como formas de vida y espacios de saber donde los estudiantes encuentran otros referentes culturales y fuentes de inspiración, y círculos de conversación con los participantes y con otros pares académicos alrededor de ejes como el rol político del maestro en contextos críticos, la memoria y la construcción de paz. En la siguiente fase, la interpretación, el análisis y la escritura se asumen como una polifonía en la que los relatos, los fundamentos teóricos y las voces de los investigadores generan una red de sentidos que se nutre de los acontecimientos narrativos en los que maestros dejan huellas de subjetividad, improntas políticas y éticas, en clave de una hermenéutica de la vida y de la experiencia donde el lenguaje es esa urdimbre a través de la cual las manifestaciones del ser y las formas del decir se despliegan.

Se pretende, con esas tramas narrativas, "Ilevar al lenguaje una experiencia, un modo de vivir $y$ de estar-en-el-mundo que le precede y pide ser dicho" (Ricoeur, 2000, p. 206). Cobra vida allí un proceso donde la explicación y la comprensión (Ricoeur, 2006) se mueven de manera pendular y constituyen dos momentos indisociables en la construcción de sentido. Finalmente, en sintonía 
con la dimensión ética de la investigación, se propone una última fase que comprende la puesta en común de los resultados del proyecto en las comunidades, así como la recepción de sus valoraciones, en un ejercicio recíproco de saberes y sentires compartidos.

\section{Resultados o relatos de experiencias pedagógicas}

Las narraciones de los maestros, las visitas a sus escuelas y las conversaciones han develado miedos y llantos contenidos frente a las realidades vividas, pero también, ese arrojo de quien, convencido de los alcances de su profesión, asume como forma de rebeldía frente a lo establecido en los regímenes de violencia, en las políticas estatales y en la desigualdad, un compromiso indeclinable que no se diezma, aunque transcurran los años y se mude de piel. Las tres experiencias que se presentan a continuación focalizan el trabajo de cuatro de los maestros participantes. Se trata de memorias que vuelven sobre su quehacer pedagógico, sobre el lugar del lenguaje en los procesos de formación que orientan, sobre sus apuestas por la construcción de paz y por un oficio de vivir esperanzado.

\section{Grullas por la paz: Ios vuelos de la ficción en tiempos de penuria}

Esta primera experiencia focaliza la trayectoria de un maestro que ha pasado gran parte de su vida en la Institución Educativa La Independencia de la Comuna 13. Está allí desde 1997, justo cuando el colegio aún no estaba construido, de modo que también él puso allí la arena, el cemento y los adobes para levantar esa edificación que constituiría un referente educativo de importancia sustantiva para el barrio El Salado. Esa arquitectura fundada en las manos de la comunidad y de los maestros tenía sus cimientos en un proyecto social y humano que tendría que encarar luego los periodos más crudos de la violencia entre los años 2000 y 2003. Justo en este tiempo, le propusieron varias veces la posibilidad de un traslado a un establecimiento ubicado en otro sector de la ciudad. No obstante, nunca se ha querido ir porque siente que el compromiso con la formación tiene sus bases en este lugar.

En su narrativa habita aún el recuerdo del tiempo en el que los actores armados rodeaban el colegio, de cuando la gente no soportaba más balaceras y muertes. Por ello, junto con otros profesores, lideraron varias iniciativas de paz en la institución para Ilamar a la calma, al respeto por la vida, al derecho a caminar las calles sin el temor a cruzar ciertas fronteras. Una de esas actividades encontró en un cuento la inspiración para animar la participación de los estudiantes. Se trataba de las "Mil grullas", de la escritora argentina Elsa Bornemann, un relato que cuenta la historia de Naomi y Toshiro, dos niños que vivían en Hiroshima, justo en el periodo en que esta ciudad japonesa sufrió las atrocidades de la bomba atómica en 1945. Después de ese acontecimiento, la amistad que existía entre los pequeños se quebranta y la niña es internada en un hospital como consecuencia de la radiación generada por el ataque nuclear. En un intento por salvar a su amiga, el niño la visita en el centro hospitalario y le lleva mil grullas de papel. Esto porque, según una leyenda japonesa, los mayores deseos -entre ellos el de prolongar la vidapodían convertirse en realidad si se construían mil figuras de esta especie en el material mencionado.

Convencidos del significado de las grullas, no solo en lo referido a la perdurabilidad de la vida, sino también como símbolo de paz, los maestros y los estudiantes de La Independencia hicieron mil grullas en origami; los pasillos del colegio se llenaron de esas pequeñas aves que querían sugerir, con su vuelo, un tiempo donde la violencia dejara de cortar las alas. En sus propósitos estaba también llevar a cabo una marcha pacífica que pretendía insistir en un jbasta ya! frente a los conflictos y el miedo. Pero los actores armados no permitieron su realización. Sin embargo, ese vuelo ficcional, creativo y simbólico que pobló la institución dejó sus ecos en el corazón de los escolares. 
Además de esta apuesta colectiva, este maestro destaca cómo a lo largo de su práctica pedagógica, el teatro ha resultado muy significativo en el trabajo con los estudiantes, no solo por los textos dramatúrgicos que abordan o por los montajes teatrales realizados, sino porque se ha convertido en una pasión que ocupa el tiempo de muchos jóvenes mientras no están en la escuela. Unido a ello, la lectura en el aula de crónicas de autores locales y nacionales ha reencontrado a los estudiantes con las amplias posibilidades de la narración y el testimonio para acercarse, desde una visión profunda y detallada, a las singularidades de quienes han persistido en la guerra, o de quienes la han evitado porque han logrado torcer los destinos que parecían inexorables.

\section{Lectura, escritura y danza: la vida en escena}

El barrio El Corazón fue uno de los epicentros de las confrontaciones armadas que tuvieron lugar en la Comuna 13 entre 2000 y 2002. Las pérdidas humanas y los efectos psicosociales generados por las hostilidades dejaron a su paso una estela de tristeza y desencanto. Se trataba de punzadas en el corazón que Ilenaban las aulas de desasosiego y de interrogantes que revoloteaban como libélulas. Ese fue el escenario que encontró una de las maestras en 2003, año en el que llegó a la institución educativa de este sector. Lejos de asumir una actitud resignada o indiferente frente a este desalentador panorama y guiada por la esperanza y la convicción de que era posible un viraje, se dio el permiso de desacomodar el currículo con sus contenidos habituales, para desatar, en el acontecimiento de la escritura, la palabra pendiente, el nudo atorado en lo más hondo, las muertes que enlutaban los días como si se trataran de un manto oscuro que cubría todo destello. De este modo, los jóvenes que cursaban los grados de secundaria dispusieron sus páginas para recobrar la voz aplastada por los golpes de la violencia. Escribir era una forma de zurcir la existencia cuando las emociones y los sueños yacían deshilachados en el suelo de las preocupaciones.

Además de estas costuras del decir en la página escrita se precisaban otros refugios. La biblioteca era uno de ellos, pero, no había libros ni estantes para los instantes de apetencia de libros. Ante la triste ausencia de un sitio para la lectura, la maestra organizó un evento comunitario que le permitió reunir fondos para dotar de material bibliográfico este espacio tan anhelado. Ese deseo se hizo realidad en un lugar donde el vuelo imaginativo y la posibilidad de beber en variadas fuentes de conocimiento ampliaron las motivaciones para permanecer en el colegio y reafirmar, en esa permanencia, un nuevo comienzo para esa juventud que no quería abandonarse al borde del precipicio de una sociedad rota.

Tres años más tarde, la maestra se vinculó a otro establecimiento de la Comuna. Se trata de la Institución Educativa Stella Vélez Londoño donde labora actualmente. Allí, junto con sus estudiantes y con otro colega dieron vida al proyecto Arte impacto, una iniciativa que, desde entonces, le ha apostado a la música, al teatro y a la danza como manifestaciones estéticas que escenifican el poder creador del sujeto y llenan la vida de persistentes movimientos.

Con la experiencia de la danza, por ejemplo, aparte de las presentaciones que se han llevado a cabo en la institución, han habitado distintos espacios de ciudad y del ámbito nacional. En uno de esos viajes tuvieron la oportunidad de conocer el mar. Un grupo de escolares ante ese inmenso horizonte de agua: una bella metáfora de vida donde las mareas y los oleajes cotidianos encuentran su orilla de esperanza.

\section{Artes y memoria histórica: entre canto y trazo, entre relato e ilustración}

En la Institución Educativa Carlos Vieco Ortiz, dos maestras decidieron apostarle, desde 2017, a la configuración y al desarrollo de una propuesta pedagógica que tuvo como centro la construcción de 
memoria histórica con los estudiantes de los grados décimo y undécimo. Pretendían, con ello, resignificar el pasado y vivirlo, como sostiene Todorov (1997), desde una memoria ejemplar, esto es, aquella que "permite utilizar el pasado con miras al presente, servirse de las lecciones de las injusticias sufridas, para combatir las que tienen vigencia hoy, abandonar el yo para ir hacia el otro" (p. 18). Se trataba de que los jóvenes volvieran a lo acontecido para hacerlos partícipes de la generación de experiencias de paz que no solo los reconciliaran consigo mismos, sino también con aquellos que desataron su rencor y sus miedos, con los barrios que los habían visto crecer, con la posibilidad de un presente menos agreste. De ese modo, los invitaban a vincularse a un propósito educativo que influía en su aprendizaje, pero también, en la recomposición social de las comunidades.

Este trabajo colegiado tuvo asidero en una propuesta de formación que encontró en la literatura, la música y la ilustración, ámbitos que favorecieron el reconocimiento de la memoria de la violencia reciente del país desde perspectivas estéticas y culturales, al tiempo que permitieron el despliegue de la creatividad y de la expresión sensible. Una de las actividades que facilitó ese desborde de imaginación de los jóvenes tuvo que ver con la composición de canciones dictadas por el gesto honesto y hondo de quien se reconoce en una historia que duele y que se empeña en sanar para que las heridas no sangren, antes bien, que admitan las costuras para cicatrizar y coser un porvenir distinto. La relevancia de este ejercicio llevó a las maestras a idear un evento de presentación donde las elaboraciones se hicieron públicas ${ }^{6}$. Fue muy grato apreciar las guitarras y las voces de los estudiantes en la musicalización de sus sueños. Dentro del repertorio presentado incluyeron una canción llamada "Cómo resisto yo" que decía:

6 El evento se realizó en la Institución Educativa Carlos Vieco Ortiz en marzo de 2018.
¿Qué vida nos espera en un futuro?

El mundo necesita nuestra ayuda,

es hora de encontrar una salida.

Tratar de remendar nuestras heridas.

Un último tema musical, titulado "Sueño", completaba esta expresión juvenil que se expandía en las aulas como esa voz decidida que muchos quisieran acallar, pero que estaba allí para alzar su tono serenamente porque en ese arrojo del canto podía estar la fuerza de la trasformación.

Yo solo quiero una sonrisa,

que el ambiente de la paz lo sintamos en la brisa,

a pesar de la injusticia hay que seguir con esta vida.

De otro lado, de la mano de la literatura, las maestras adentraron a los estudiantes en una realidad ficcional e histórica que amplió sus horizontes de reflexión y las comprensiones sobre la condición humana llevada a las circunstancias más complejas, cuando se encuentra de frente con la violencia. Obras como No nacimos pa' semilla. La cultura de las bandas juveniles en Medellín, de Alonso Salazar; El atravesado, de Andrés Caicedo ${ }^{7}$, y El olvido que seremos, de Héctor Abad Faciolin$\mathrm{ce}^{8}$, contribuyeron a desnaturalizar la violencia, a desacomodar el sentir, al tiempo que invitaron a hacer memoria escrita sobre la propia vida y sus tensiones en los ámbitos familiar, social, comunitario. La escritura revelaba que el vacío, la soledad, el dolor y la violencia no eran un asunto del pasado en las trayectorias vitales de los jóvenes o en el devenir de sus barrios. Fenómenos como la ausencia de uno de los padres en el hogar, el maltrato, la drogadicción, el pandillismo, las confrontaciones entre bandas delincuenciales, entre otros, aún estaban presentes en la cotidianidad y seguían

$7 \quad$ Este libro fue publicado en 1975 y recrea la vida de un joven que se vincula a la actividad de las pandillas en Cali. Peleas, cine y subversión del orden convencional son las constantes de los personajes en la cotidianidad de la época.

8 Obra publicada en 2006 en la que Abad Faciolince teje una memoria sobre la vida de su familia y, de manera especial, sobre su padre Héctor Abad Gómez, un médico y defensor de derechos humanos asesinado en 1987 en Medellín. 
influyendo en las emociones, en las formas de ver el mundo, en las relaciones intersubjetivas. Escribirse y narrarse tras las inquietudes animadas por las lecturas literarias resultaba un acontecimiento tan necesario como significativo en esas vidas que se confesaban en la búsqueda de una identidad que les permitiera afrontar los desafíos y hacer unas escogencias distintas para la existencia. Se trataba de idear acciones pacifistas en medio de los conflictos que sacudían el día a día. En la figura 1 se observa una de las elaboraciones derivadas de este proceso. Allí, los estudiantes plasman sus sentires y sus propósitos alrededor de la memoria y la construcción de paz.

Allí estaba la convicción de las maestras: un trabajo pedagógico serio y bien fundamentado podía trazar esos nuevos caminos. Por ello, además de lo anterior, incluyeron un recorrido con los estudiantes por las calles y los barrios de la Comuna 13. Se trataba de habitar esos lugares de la memoria, ya no como paisaje naturalizado sino desde la pregunta por las significaciones y por los relatos que estos develaban. En ese transitar, era recurrente encontrarse con los grafitis que los jóvenes de distintos colectivos y corporaciones artísticas y culturales han plasmado en muros y paredes. Estos son como ese gran cuaderno abierto al público para contar, desde la perspectiva del arte, la opresión y la resistencia que ha vivido este territorio en las últimas décadas. Reconocer y discutir sobre esas narrativas visuales situaba a los escolares en un pasado y un presente que no les era ajeno, que les pertenecía, que los reclamaba. Unido a ello, la conversación con personas de los barrios les permitió reconocer testimonios sobre las dinámicas sociales de la zona desde visiones alternativas.

Este habitar reflexivo e interrogativo de los territorios, de la propia vida y del saber, desde un acto educativo que promueve la recordación y la problematización del pasado, constituye una apuesta ética y política insoslayable en los contextos escolares. En este sentido, "no es posible una educación que no tenga como punto de referencia el recuerdo y, junto a ello, el compromiso por asentar la construcción de la sociedad en una cultura anamnética" (Bárcena y Mélich, 2000, p. 26).

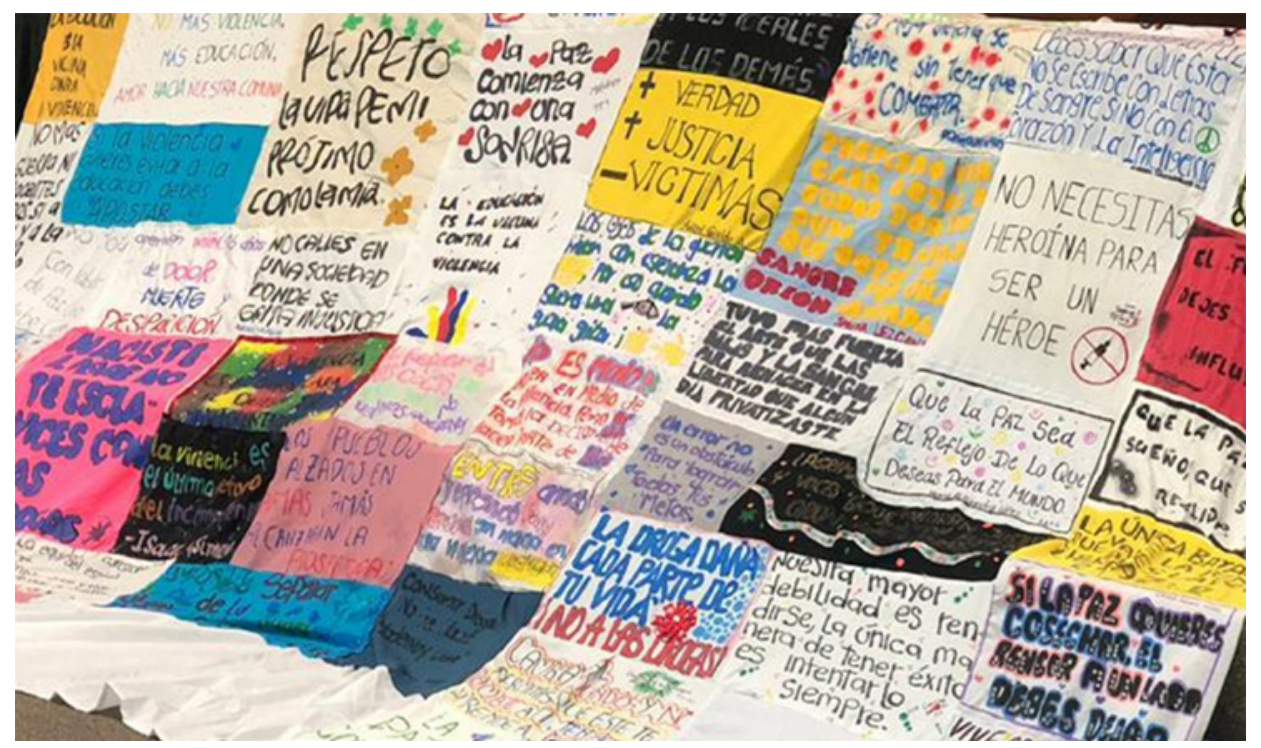

Figura 1. Colcha de la memoria, elaborada por estudiantes y profesoras de la Institución Educativa Carlos Vieco Ortiz, 2018

Fuente: elaboración propia. 
Una cultura que interpela el olvido como acción necesaria para la no repetición, para la reconciliación y la invención, ante las desolaciones y dislocaciones que deja la violencia.

De este modo, contrario a la sensación que podrían dejar libros ya mencionados como No nacimos pa' semilla, estas dos maestras y sus estudiantes confiaban aún en que, en este sector de la ciudad de Medellín, los niños, niñas y jóvenes sí podían cultivarse como las semillas de un tiempo volcado al cuidado de la vida, de un porvenir capaz de recobrar el sentido del futuro porque la fragilidad y el carácter efímero del existir pueden conjurarse cuando las aulas promueven un pensamiento sensible, espacios hospitalarios donde el rostro del otro no pasa inadvertido, prácticas donde el lenguaje no se agota en una gramática fría sino en un campo de posibilidades expresivas desde donde se puede disentir y sentar una posición.

Tanto en esta experiencia como en las anteriores, se revelan unas subjetividades que insisten en "la posibilidad de un mundo estructurado sobre la no violencia" (Butler, 2020, pp. 53-54), en un espacio de acogida capaz de encarar las heridas sociales, de otorgarles un carácter reparador y vinculante a las relaciones pedagógicas. De acuerdo con Kaplan (2016), "la reparación simbólica es un acto educativo que habilita experiencias escolares menos traumáticas y deja como legado de transmisión una actitud ética con el otro (p. 119). Estos espacios de acogida son un Ilamamiento a otras instituciones, cuyos currículos continúan obsesionados por el control y la prescripción; estas también son expresiones violentas que limitan el pensar, el sentir y el movimiento de la vida. Sin amplitud de pensamientos y sin horizontes libertarios será muy difícil consolidar las transformaciones que requieren las comunidades históricamente afectadas por múltiples hostilidades, por el abandono de las instancias estatales y por las estigmatizaciones de algunos sectores de la sociedad que, desde una mirada determinista, sentencian los destinos vitales.

\section{Conclusiones}

Poner la mirada en la escuela en contextos asediados por la violencia potencia el reconocimiento de otras formas de enseñar, de hacer escuela; ofrece la oportunidad de habitar esos territorios donde hay otras narrativas distintas a las oficiales. Permite, desde el campo de la educación, iluminar ámbitos de reflexión, de comprensión y de acción pedagógica que resultan fundamentales para seguir pensando el papel del maestro colombiano y latinoamericano en la compleja trama de conflictos históricos, políticos y sociales que han marcado el devenir de la región.

Allí donde el grito se ha impuesto, donde los renglones se han llenado de nombres sentenciados, donde la palabra totalizante ha anulado la potencia del matiz, donde el silencio no ha sido siempre experiencia contemplativa sino mutismo ante el miedo, donde el diálogo se ha encasillado en un solo tono, donde la violencia ha aturdido con furor, también han cobrado vida manifestaciones del lenguaje que enfatizan en su carácter político, estético y social, y aportan de manera decidida en la interpelación de los discursos y de las acciones violentas, así como en la configuración de subjetividades y en la generación de ámbitos de creación donde se recobran las formas de actuación libertarias. Cuando las escuelas invitan a vivir el lenguaje desde la reflexividad, la invención y la participación en distintas prácticas de la cultura, se asiste al devenir y a la promesa de trayectorias de niños, niñas y jóvenes en sintonía con un compromiso de humanidad capaz de poner su semilla en las nuevas siembras, a propósito de la aridez del mundo.

Las experiencias pedagógicas llevadas a cabo por los maestros en la Comuna 13 tienen que ver con acciones disruptivas que no se resignan a habitar en la imposibilidad y en el miedo. Los horizontes curriculares que guían su quehacer no bajan la cabeza ante los conflictos, la desigualdad social y la exclusión que han permeado las 
dinámicas de los barrios y las escuelas, antes bien, levantan el rostro y fijan la mirada en un tejido vinculante donde la relación entre sujeto, saber, vida y lenguaje acontecen en un entramado sin obsesiones por las calificaciones, por las políticas del rendimiento y la eficacia, por las tareas desmedidas que no dejan tiempo para respirar. En ese deslinde de la prescripción, en ese gesto atento a las realidades socioculturales y a la construcción subjetiva, se despliegan prácticas de resistencia que son la expresión de un malestar creativo ante el mundo dado, de un quehacer que desata un relato de esperanza actuante, un relato que no se doblega, aunque el tiempo persista en la densidad de las sombras.

\section{Reconocimientos}

El artículo se deriva de una investigación doctoral que lleva a cabo la autora en el marco del Doctorado en Educación de la Universidad de Antioquia.

\section{Referencias bibliográficas}

Bárcena, F. (2000). El aprendizaje como acontecimiento ético. Sobre las formas del aprender. Enrahonar, 31, 9-33. DOI: https://doi.org/10.5565/rev/ enrahonar.406

Bárcena, F. y Mèlich, J. C. (2000). La educación como acontecimiento ético. Natalidad, narración y hospitalidad. Barcelona: Paidós.

Boff, L. (2002). El cuidado esencial. Madrid: Ediciones Trota.

Bolívar, A. (2002). ¿De nobis ipsis silemus?: epistemología de la investigación biográfico-narrativa en educación. Revista Electrónica de Investigación Educativa, 4(1), 1-26. Recuperado de https://redie. uabc.mx/redie/article/view/49

Bolívar, A., Domingo J. y Fernández M. (2001). La investigación biográfico narrativa en educación. Madrid: La Muralla.

Bruner, J. (2013). La fábrica de historias. Derecho, literatura, vida. Buenos Aires: Fondo de Cultura Económica.
Butler, J. (2020). Sin miedo. Formas de resistencias a la violencia de hoy. Barcelona: Penguin Random House.

Castoriadis, C. (1997). El avance de la insignificancia. Buenos Aires: Editorial Universitaria de Buenos Aires.

Centro Nacional de Memoria Histórica (CNMH) (2014). Textos corporales de la crueldad. Memoria histórica y antropología forense. Bogotá.

Cortés, S., Pérez T. y Guerra L. (2016). La escuela colombiana: entre la nuda vida y la biopotencia. Revista Colombiana de Educación, 71, 383-397. DOI: https://doi.org/10.17227/01203916.71rce383.397

Durán, N. (2013). Reescribir entre cuerpos andando caminos po(e)sibles. Propuesta de nuevos escenarios para la educación y la investigación educativa. Revista Educación y Pedagogía, 25(65) 79-105. Recuperado de https://revistas.udea.edu.co/index.php/ revistaeyp/article/view/328770

Foucault, M. (1975). Vigilar y castigar. México: Siglo XXI.

Foucault, M. (2008). Tecnologías del yo. Buenos Aires: Paidós.

Freire, P. (2005). Pedagogía del oprimido. México: Siglo $\mathrm{XXI}$.

Grupo de Memoria Histórica (2011). La huella invisible de la guerra: desplazamiento forzado en La Comuna 13. Bogotá: Grupo de Memoria Histórica, Ediciones Semana, Taurus.

Kaplan, C. (2016). Cuidado y otredad en la convivencia escolar: una alternativa a la ley del talión. Pensamiento Psicológico, 14(1), 119-130. DOI: https:// doi.org/10.11144/javerianacali.ppsi14-1.coce

Lizarralde, M. (2012). Ambientes educativos y territorios del miedo en medio del conflicto armado: estudio sobre escuelas del Bajo y Medio Putumayo. Revista Colombiana de Educación, (62), 1-19. DOI: https://doi.org/10.17227/01203916.1621

Lozano P. (2017). Historias de un país invisible. Bogotá: Ediciones SM.

Mèlich, J. C. (2010). Ética de la compasión. Barcelona: Herder.

Meirieu, P. (1996). Frankenstein educador. Barcelona: Laertes. 
Ricoeur, P. (2000). Narratividad, fenomenología y hermenéutica. Anàlisi: quaderns de comunicació i cultura, (25), 189-207. Recuperado de https://www. raco.cat/index.php/Analisi/article/view/15057

Ricoeur, P. (2004). Tiempo y narración. Tomo I: Configuración del tiempo en el relato histórico. México: Siglo XXI.

Ricoeur, P. (2006). Del texto a la acción: ensayos de hermenéutica II. Buenos Aires: Fondo de Cultura Económica.
Thomas, D. (1955). Poemas. Madrid: Ediciones Rialp. Todorov, T. (1997). Usos y abusos de la memoria. En Corporación Región (ed.), Memoria y ciudad (pp. 10-29). Medellín.

Torres C. (2006). Subjetividad y sujeto: perspectivas para abordar lo social y lo educativo. Revista Colombiana de Educación, 50, 86-103. DOI: https://doi.org/10.17227/01203916.7741 